\title{
Strategi Public Relations Dalam Mendukung Kinerja BAAK STIKIM
}

\author{
Fabriansyah Nataly ${ }^{1}$, Sunarto ${ }^{2}$, Hanafi Murtani ${ }^{3}$ \\ ${ }^{1,2,3}$ Universitas Prof. Dr. Moestopo Beragama \\ Email correspondent: febrixvai@gmail.com
}

\begin{abstract}
Abstrak
Tujuan dari penelitian ini adalah untuk mengetahui strategi public relations di bidang costumer relations, hambatan-hambatan apa saja yang dihadapi, dan gambaran kinerja BAAK STIKIM. Metode Penelitian yang digunakan dalam penelitian ini adalah metode kualitatif deskriptif dengan paradigma konstruktivis. Dari hasil temuan penelitian dan pembahasan dapat diketahui bahwa strategi public relations masih kurang maksimal dikarenakan tugas-tugas public relations dalam pelayanan informasi di STIKIM masih dilakukan secara fungsional manajemen lalu BAAK STIKIM juga telah berupaya melakukan model public relations yang Two Way Symmetrical. Masih banyak permasalahan dan hambatan-hambatan yang harus dihadapi terkait kinerja BAAK STIKIM, terutama dalam berkomunikasi dan pandangan tentang kinerja BAAK STIKIM dari nara sumber terutama informan masih belum optimal dalam memberikan layanan informasi.
\end{abstract}

Kata Kunci: strategi, customer relations, kinerja

\begin{abstract}
The purpose of this research is to know the public relations strategy in the field of customer relations, what obstacles are faced, and the performance description BAAK STIKIM. The research method used in this research is a descriptive qualitative method with a constructivist paradigm. From the findings of research and discussion, it can be seen that the public relations strategy is still less than the maximum because the tasks of public relations in information services in STIKIM is still done functional management and then BAAK STIKIM has also tried to do public relations model that Two Way Symmetrical. There are still many problems and obstacles to be faced related to the performance of BAAK STIKIM, especially in communicating and views about the performance of STAKIM BAAK from informants, especially informants are still not optimal in providing information services.
\end{abstract}

Keywords: strategy, customer relations, performance 


\section{Pendahuluan}

Perguruan Tinggi sebagai salah satu institusi pendidikan adalah suatu lembaga yang memberikan pelayanan publik, seperti layaknya perusahaan-perusahaan jasa masyarakat pada umumnya. Persaingan antar perguruan tinggi yang semakin ketat membuat perguruan tinggi harus selalu menjaga kualitas pelayanan bagi para stakeholder (para dosen, mahasiswa, orang tua mahasiswa, dunia usaha, calon mahasiswa dan alumni) terutama dalam perolehan informasi terkait akademik sehingga tetap menjadi pilihan utama bagi mahasiswa. Pengelolaan secara profesional akan dapat memberikan kualitas pelayanan yang memuaskan. Usaha meningkatkan pelayanan yang diberikan oleh suatu institusi pendidikan, salah satu faktor yang juga tidak bisa diabaikan seperti kualitas sumber daya manusia yang memadai (kompetensi administrasi/pelayanan) dalam hal ini adalah tenaga kependidikan di perguruan tinggi tersebut. ${ }^{1}$

Peran tenaga kependidikan adalah untuk menciptakan suasana pendidikan yang bermakna (menyenangkan, kreatif, dinamis, dan dialogis) dalam rangka membantu meningkatkan mutu pendidikan. Berkaitan dengan tenaga kependidikan yang mengelola layanan pendidikan dalam hal teknis administrasi akademik ditangani oleh Bagian Administrasi dan Akademik Kemahasiswaan (BAAK).

Bagian Administrasi dan Akademik Kemahasiswaan (BAAK) merupakan salah satu bentuk dari sebuah organisasi di salah satu perguruan tinggi, seperti halnya di STIKIM (Sekolah Tinggi Ilmu Kesehatan Indonesia Maju). Sekolah tinggi ini merupakan salah satu perguruan tinggi swasta yang memiliki banyak program studi kesehatan. Diantara beberapa sekolah tinggi kesehatan, STIKIM ini termasuk perguruan tinggi yang cukup baik dari segi kualitas dan kuantitas karena satu-satunya sekolah tinggi yang mempunyai Program Pascasarjana. Sementara di sekolah tinggi kesehatan yang lain hanya memiliki di DIII, DIV atau S1. ${ }^{2}$ Bagian Administrasi dan Akademik Kemahasiswaan STIKIM memiliki peran membantu mahasiswa sehingga tingkat ketergantungan informasi terhadap layanan menjadi sangat besar, apalagi fenomena sekarang banyak kita lihat bahwa mahasiswa khususnya kurang mendapatkan informasi dari membaca dikarenakan banyak yang kurang minat membaca informasi seputar akademik di kampus. Pada umumnya para mahasiswa hanya menantikan informasi dari layanan Bagian Administrasi dan Akademik Kemahasiswaan saja, sehingga kebutuhan akan layanan seputar akademik semakin dirasakan.

Bagian Administrasi dan Akademik Kemahasiswaan STIKIM terdiri dari tenaga kependidikan yang berdiri paling depan (gatekeeper) dalam pelayanan kepada mahasiswa dan dosen serta masyarakat lainnya yang memiliki kepentingan terhadap STIKIM. Adapun tugas pokok tenaga administrasi akademik STIKIM meliputi: ${ }^{3}$ (1) Penyediaan sarana (kelas, laboratorium, dll). (2) Penyediaan pedoman dan prosedur layanan (surat, isi KRS, cek nilai, cuti, aktif, ijazah, dll). (3) Layanan Kartu Rencana Studi (KRS) Mahasiswa. (4) Layanan Perkuliahan (absen, SAP pengajaran, konfirmasi dosen, dll). (5) Evaluasi Perkuliahan (cek EDOM, rapat kelas, dll). (6) Serta layanan administrasi akademik lainnya yang menjadi bagian dari layanan administrasi akademik unit kerjanya, termasuk dari program studi (rekap pertemuan dosen, membuat jadwal UTS/UAS, dll).

Dengan demikian, tenaga administrasi akademik STIKIM diharapkan mampu melayani dengan prima sesuai dengan aturan dan kebutuhan pemangku kepentingan (stakeholder), khususnya mahasiswa. Untuk menjalankan tanggung jawab serta fungsinya sebagai tenaga administrasi akademik diperlukan juga keahlian dalam pelayanan sebagai alat utamanya.

Tenaga administrasi akademik perlu memberikan pelayanan terbaik kepada mahasiswa sehingga kegiatan organisasi dapat berjalan dengan baik. Sebaliknya, jika tenaga administrasi akademik tidak dapat memberikan pelayanan terbaik kepada mahasiswa maka tenaga administrasi tersebut tidak dapat menjalankan fungsinya sebagaimana mestinya.

Pernyataan di atas menjelaskan bahwa tanpa adanya kinerja yang baik oleh tenaga Bagian 
Administrasi dan Akademik Kemahasiswaan STIKIM kepada mahasiswa maka tujuan BAAK tersebut tidak dapat dicapai secara optimal. Jika dalam pelayanan BAAK STIKIM terdapat kesalahan (banyak komplain, miss communication, tentative informasi, tumpang tindih informasi, dll) maka aktivitas perkuliahan/akademik di STIKIM tidak dapat berjalan secara optimal.

Peneliti melihat Bagian Administrasi dan Akademik Kemahasiswaan (BAAK) di beberapa kampus lain tidak jauh berbeda dengan BAAK STIKIM baik dalam kedudukan, tugas pokok, dan fungsinya. Hanya saja Bagian Administrasi dan Akademik Kemahasiswaan (BAAK) di kampus lain sudah ada yang berbasis online. Jadi mahasiswa bisa langsung melihat informasi-informasi akademik ke website BAAK kampus yang dituju oleh mahasiswa tersebut. Tentunya ini merupakan hal yang baik dalam suatu kinerja dari Bagian Administrasi dan Akademik Kemahasiswaan (BAAK) kampus yang bersangkutan.

Di Bagian Administrasi dan Akademik Kemahasiswaan (BAAK) STIKIM memiliki petugas Front Office (FO) yang mempunyai job desk melakukan pelayanan terhadap mahasiswa. Disini peniliti melihat Front Office BAAK STIKIM harus melayani mahasiswa dengan berbagai macam karakter yang terdiri dari berbagai macam program studi.

Petugas front office kerap dibantu oleh anggota BAAK STIKIM yang lain dalam melakukan pelayanan. Anggota BAAK biasanya akan membantu jika suasana di front office ramai oleh mahasiswa yang datang dengan berbagai macam keperluan, sehingga dengan keadaan seperti itu BAAK STIKIM harus melakukan aktivitas komunikasi kepada publik eksternalnya (mahasiswa)(4)

Terkait dengan aktivitas komunikasi yang dilakukan BAAK STIKIM saat ini, maka tidak akan lepas dari fungsi komunikasi. Menurut Onong Uchjana Effendy ${ }^{5}$ ada empat fungsi komunikasi yaitu menyampaikan informasi, mendidik, menghibur, dan mempengaruhi. Untuk bisa sampai ke fungsi komunikasi tersebut, maka BAAK STIKIM harus melakukan beberapa hal yang terkait dengan strategi komunikasi public relations terhadap mahasiswa. Peneliti juga melihat masih adanya permasalahan dalam pelayanan BAAK STIKIM yaitu munculnya keluhan secara tertulis dalam bentuk "form keluhan dan saran" di kotak saran yang disediakan oleh BAAK STIKIM, lalu sering terjadi perbedaan persepsi dari mahasiswa dengan BAAK STIKIM sehingga menimbulkan opini public (mahasiswa) yang tidak sesuai dengan harapan. Disisi lain setiap anggota BAAK STIKIM berkomunikasi dengan cara yang berbeda baik verbal maupun non verbal, dikarenakan dari masing-masing anggota memiliki sifat dan latar belakang yang berbeda- beda. Terkadang hal ini bisa juga memicu perbedaan persepsi dari public eksternalnya (mahasiswa). ${ }^{6}$

Hal ini tidak lepas dari kegiatan public relations (PR) yang salah satunya melakukan aktivitas customer relations. Customer relations tidak dapat dipisahkan dari peranan public relations dalam kegiatannya. Ini menjadi salah satu bentuk komunikasi BAAK STIKIM yang terencana baik itu ke dalam maupun keluar antara BAAK STIKIM dengan khalayaknya. Peran Public Relations harus mendukung kinerja organisasi dalam membangun relasi yang saling menguntungkan dengan stakeholder eksternal baik pemegang saham, rekan kerja perusahaan ataupun konsumen. ${ }^{7}$ Tujuan Penelitian adalah untuk mengetahui salah satu fungsi strategi BAAK STIKIM dalam mendukung kinerja.

\section{Metode}

Penenelitian ini menggunakan metode penelitian kualitatif deskriptif dengan paradigma konstruktivis karena untuk mengetahui bagaimana strategi public relations dalam mendukung kinerja BAAK STIKIM.

Dalam penelitian ini, penulis melakukan penelitian yang bertempat di Sekolah Tinggi Ilmu Kesehatan Indonesia Maju (STIKIM) yang terletak di Jalan Harapan, Gedung HZ No. 50. Alasan penulis memilih tempat ini dikarenakan kampus ini merupakan kampus swasta di bidang kesehatan yang cukup 
banyak mahasiswanya. Selain itu lokasi STIKIM ini dekat dari rumah peneliti.

Dalam melaksanakan penelitian ini waktu yang dipergunakan oleh penulis untuk memperoleh data yang diperlukan adalah mulai tanggal 20 September 2016- November 2017.

Subjek dan Objek Penelitian adalah terdiri dari key Informan terdiri dari 1 wakil ketua STIKIM, 1 ketua BAAK dan informan sebanyak 6 orang. Obyek penelitian ini adalah STIKIM melalui bagian BAAK. Sumber data yang diambil menggunakan sumber data primer dan sekunder. Tehnik pengumpulan data yaitu dilakukan dengan wawancara, observasi,studi kepustakaan.

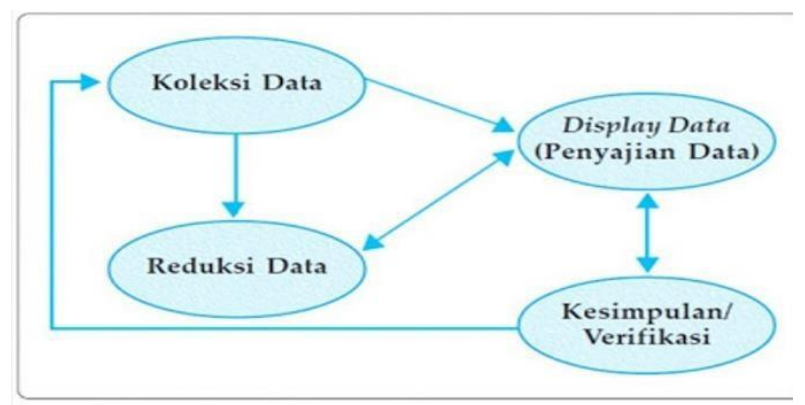

Gambar 1. Teknik Analisis Data

Untuk Keabsahan data, peneliti juga menggunakan triangulasi dalam teknik pengumpulan data. Triangulasi adalah teknik pengumpulan data yang bersifat menggabungkan dari berbagai teknik pengumpulan data dan sumber data yang telah ada. ${ }^{8}$ tujuan dari triangulasi bukan untuk mencari kebenaran, tetapi kepada peningkatan pemahaman peneliti terhadap apa yang telah ditemukan. Sebab hal ini juga berawal dari tujuan penelitian kualitatif, yakni lebih kepada pemahaman subyek terhadap dunia sekitarnya. Menurut Sugiono, ${ }^{9}$ triangulasi dapat dibedakan menjadi dua macam, yaitu triangulasi teknik dan triangulasi sumber. Triangulasi teknik adalah peneliti menggunakan teknik pengumpulan data yang berbeda-beda untuk mendapatkan data dari sumber data yang sama. Triangulasi lebih meliputi sejumlah peristiwa yang terjadi. Sedangkan triangulasi sumber adalah peneliti memperoleh data dan sumber yang berbeda-beda dengan teknik yang sama.

Triangulasi dalam peneliti ini adalah triangilasi sumber karena peneliti melakukan cara yang sama dalam mengumpulkan data kepada sumber yang berbeda. Triangulasi sumber dapat meningkatkan pemahaman peneliti tentang suatu persoalan yang ditemukan di lapangan. ${ }^{10}$

\section{Hasil dan Pembahasan}

Setelah peneliti mewawancarai beberapa mahasiswa STIKIM, peneliti menemukan beberapa masalah terkait dengan kinerja BAAK STIKIM antara lain kurang baiknya cara berkomunikasi yang dilakukan BAAK STIKIM, munculnya keluhan secara tertulis yang berada di kotak saran, banyaknya perbedaan persepsi antara mahasiswa dengan BAAK STIKIM. Selain itu, kadang adanya kurang koordinasi job desk atau titipan pekerjaan antara anggota penanggung jawab BAAK STIKIM yang mana itu berkaitan dengan kebutuhan mahasiswa.

Sudah jelas sekali dari hasil wawancara beberapa mahasiswa, terdapat masalah terkait strategi public relations dalam mendukung kinerja BAAK STIKIM. Disini peneliti melihat BAAK STIKIM memang perlu menerapkan strategi public relations melalui komunikasi yang baik. Public relations menghubungkan kepentingan organisasi dengan publiknya, sehingga ia harus dapat menggali dan mengenali informasi sebanyak- banyaknya tentang publiknya, apakah itu minat, kebutuhan, keluhan dan lain-lain yang berkaitan dengan publik sasarannya. Public relations dituntut mengadakan komunikasi yang efektif, yaitu sebuah komunikasi yang berorientasi kepada komunikan atau publiknya. 
Customer relations tidak dapat dipisahkan dari peranan Public relations dalam kegiatannya. ${ }^{11}$ Karena dalam kegiatan Public relations juga melakukan customer relations. Public relations mempunyai peranan dalam kepuasan pelanggan. Kegiatan Public relations meliputi hubungan pers, publikasi, komunikasi perusahaan dan lobby, serta menjalin hubungan baik dengan konsumen. ${ }^{12}$

Penelitian ini menunjukkan bahwa kedudukan public relations di STIKIM ini dilakukan secara fungsional manajemen yang merangkap ke beberapa divisi lain. Di STIKIM memang belum mempunyai SDM yang mempu untuk melakukan kegiatan public relation tersebut dan belum membutuhkan peran dan fungsi public relations dalam perusahaannya dikarenakan ukuran dari organisasi ini belum terlalu besar seperti perusahaan bonafit lainnya. Seharusnya tentu sangat penting sekali keberadaan departemen public relations di suatu perguruan tinggi, khususnya di STIKIM. ${ }^{6}$

Bagaimanapun penerapan strategi public relations dalam mendukung kinerja BAAK STIKIM ini, tentunya tidak akan lepas dari konteks komunikasi organisasi baik teori dan praktiknya. Dalam hal ini komunikasi diperlukan sehingga dapat menciptakan mobilitas sosial yang cukup dinamis dan baik. Hal ini sejalan dengan BAAK STIKIM yang selalu mengadakan rapat berkoordinasi untuk memberikan pendapat dan beberapa pandangan yang berkaitan dalam memberikan informasi untuk bisa lebih baik lagi ke mahasiswa. BAAK STIKIM yang sudah semaksimal mungkin memberikan yang terbaik dalam berkomunikasi dan membina hubungan baik ke pihak internal sendiri seperti divisi-divisi lain yang ada di STIKIM dan pihak eksternal yang mana disini adalah mahasiswa, klien, orang tua mahasiswa, tamu dari orang yang berkepentingan, dan masyarakat sekitar.

BAAK STIKIM saat ini juga sedang meningkatkan sistem jaringan online jadi segala kebijakan atau informasi yang terkait dengan perkuliahan lalu pengajaran, jadwal, dan lain-lain diinformasikan via website. Selain dengan website, biasanya BAAK STIKIM juga memasang pengumuman informasi di mading- mading setiap lantai dan supaya lebih efektif lagi BAAK STIKIM juga menyampaikan informasi dari mulut ke mulut yang biasa disebut "word of mouth". Tidak hanya BAAK STIKIM, tapi unit-unit lain termasuk perpustakaan, bagian keuangan, kemudian unit-unit yang lain juga terkoneksi dengan sistem online".

Konteks Public Relations dari segi fungsi, strategi dan model Public Relations ditambah dengan ranah customer relations sangat diperlukan dalam penelitian ini. Hal ini sejalan dengan BAAK STIKIM yang mana pada saat mahasiswa datang ke BAAK akan ditangani atau dilayani langsung oleh front office, jika si mahasiswa ini belum puas dengan informasi yang sudah diberikan oleh front office, biasanya front office minta bantuan kepada penanggung jawab akademik yang terkait untuk memberikan informasi yang dibutuhkan oleh mahasiswa tersebut. Selain itu BAAK STIKIM melakukan beberapa tahapan dalam menangani keluhan mahasiswa. Pertama komunikasi, agar tidak terjadi mis communication maka BAAK STIKIM harus bisa memperbaiki komunikasi saat menyampaikan informasi kepada mahasiswa maupun saat berkoordinasi di dalam pihak internal BAAK STIKIM itu sendiri. Jadi, kalau komunikasi dari pihak BAAK STIKIM bagus dan cara menyampaikan informasinya jelas, pasti pihak eksternal yang dimaksud disini mahasiswa bisa menerima jawaban dari pertanyaan - pertanyaan atau keluhan yang mereka sampaikan. Yang kedua adalah rapat evaluasi dimana setiap bulan anggota BAAK STIKIM meningkatkan keterampilan dan pengetahuan dari masing-masing anggota agar dapat melayani kepentingan mahasiswa dengan baik. Dan yang terakhir adalah bagaimana caranya menjaga kekompakan yang baik antar anggota BAAK STIKIM. ${ }^{13}$

Pendekatan kerja sama diperlukan dalam operasional BAAK STIKIM. BAAK STIKIM menganggap mahasiswa sebagai teman agar bisa bekerja sama dan bisa saling menguntungkan. Maksudnya dianggap sebagai teman di sini adalah BAAK STIKIM melayani dengan berkomunikasi yang membuat mahasiswa nyaman untuk datang ke BAAK untuk bertanya atau mengetahui yang berkaitan dengan informasi jadwal kuliah, informasi tentang ujian, atau apapun. Jadi mahasiswa tidak sungkan karena BAAK STIKIM memberikan pelayanan yang maksimal dan yang jelas membuat 
mahasiswa paham bahwa bertanya di BAAK itu bisa mendapatkan informasi yang baik, lengkap, dan jelas. ${ }^{6}$ Disini seharusnya BAAK STIKIM bisa melakukan beberapa penerapan strategi public relations dimulai dari apa yang disebut dengan Public Relations planning karena jika BAAK STIKIM mempunyai perencanaan Public Relations yang baik maka tentu saja hasilnya juga baik. Misalnya dalam setahun akan melakukan apa saja, kalau ada kegiatan yang sifatnya terjadwal apa yang harus dilakukan, kalau ada sesuatu yang tiba-tiba bermasalah jadi bisa diantisipasi, jadi semua kembali kepada perencanaan. Karena ada istilah atau pepatah yang mengatakan "if you fail to plan, you plan to fail", jika kamu gagal merencanakan sesuatu sesungguhnya kamu sedang merencanakan kegagalan.

Peneliti melihat BAAK STIKIM melakukan model public relations yang Two Way Symmetrical, karena BAAK banyak memecahkan masalah dan berusaha menghindari konflik dengan memperbaiki pemahaman publik untuk membangun saling pengertian dukungan dan menguntungkan bagi kedua belah pihak, walaupun masih banyaknya hambatan atau kendala yang dihadapi BAAK STIKIM dalam penerapan strategi public relations tersebut. ${ }^{4}$

Dalam strategi public relations yang dilakukan BAAK STIKIM dalam mendukung kinerja tentunya tidak semulus yang diharapkan. Ada saja beberapa permasalahan dan hambatan yang harus dihadapi BAAK STIKIM dalam melakukan strategi tersebut.

Salah satu permasalahan yang muncul yaitu front office BAAK STIKIM hanya di jaga oleh satu orang saja dalam melayani ratusan mahasiswa dari berbagai program studi. Khususnya di hari sabtu dimana mahasiswa STIKIM itu banyak sekali sehingga membuat front office BAAK STIKIM keteteran dan kewalahan dalam menghadapi mahasiswa. Peneliti melihat satu orang front office BAAK STIKIM untuk menghandle sekian banyak orang, maka peneliti merasa perlu ditambahnya satu atau dua orang front office BAAK STIKIM lagi dan mungkin bisa dibuat pembagian waktu, seperti ada yang datang harus lebih pagi dan ada yang pulang harus lebih malam sehingga kalau ada dua atau tiga front office bisa saling menggantikan.

Menurut peneliti, cara berkomunikasi yang dilakukan oleh tiap anggota BAAK STIKIM berbedabeda dikarenakan adanya perbedaan latar belakang lingkungan dan budaya. Ada yang berbicaranya tutur katanya rapih tertata, ada yang masih terbawa bahasa sehari-hari, ada yang gesture tubuhnya kurang baik, sehingga banyak mahasiswa yang kurang paham bahkan menimbulkan perbedaan persepsi dengan apa yang sampaikan oleh BAAK STIKIM. ${ }^{14}$

Peneliti juga melihat adanya komunikasi yang tidak efektif antara mahasiswa dengan BAAKnya seperti terjadi miss communication, lalu terlalu banyak dan ramainya mahasiswa- mahasiswa di sekitar ruangan BAAK STIKIM sehingga suka menimbulkan kesalahpahaman, terkadang emosi, dan suka muncul ketidakpercayaan terhadap informasi yang disampaikan antara mahasiswa dengan penanggung jawab BAAK STIKIM.

Selanjutnya, customer services merupakan salah satu bagian tugas dari customer relations dalam memberikan pelayanan informasi kepada konsumen. Pada dasarnya customer relations merupakan kegiatan yang diupayakan bagi terciptanya hubungan yang harmonis antara perusahaan dengan publik eksternal. Saat observasi, peneliti melihat ada saja 1 atau 2 orang yang tidak puas dengan pelayanan yang BAAK STIKIM berikan. Saat BAAK STIKIM melayani mahasiswa yang harusnya senyum, salam, dan menyapa tetapi mungkin dikarenakan beban kerja yang terlalu berat, lalu kekurangan pegawai, ditambah saat semakin sore semakin tidak ramah mukanya, terjadilah keluhan tersebut. ${ }^{6}$

Peneliti juga melihat BAAK STIKIM mempunyai satu ketua dan lima orang partner kerja di yang mana masing-masing menjadi penanggung jawab program studi. Dari kelima orang ini masing-masing individu unik-unik ada yang suka datang telat, ada yang komunikasinya kurang bagus, ada yang sering tidak komunikasi atau operan pekerjaan lalu tiba-tiba dia menghilang tanpa izin, entah makan siang, entah apa yang dilakukannya. Ini salah satu hambatan juga dimana BAAK STIKIM mau memberikan pelayanan terbaik tapi dari anggota BAAK STIKIM sendirinya atau dari masing-masing individunya 
saja belum aware atau peka terhadap tanggung jawabnya. Selain itu, terkadang mahasiswa berulangulang bertanya terkait informasi yang sudah BAAK berikan, bahkan sampai ada mahasiswa yang lain padahal masih dari kelas yang sama lalu mengulang-ulang pertanyaan yang sama. Jelas sekali keterbukaan dan konsistensi terhadap langkah-langkah yang diambil untuk memperoleh keyakinan orang lain sangat kurang dan tentunya strategi komunikasi dan beberapa fungsi public relations disini yang harus ditekankan. Menurut peneliti hal-hal kecil seperti ini sebenarnya jadi hambatan dan sampai saat ini BAAK STIKIM masih berusaha untuk memperbaiki dan meningkatkan kinerja supaya lebih maksimal lagi. ${ }^{15}$

Seharusnya dalam pelayanan BAAK STIKIM tidak boleh seperti ini. Selain BAAK, sebenarnya di kampus STIKIM ini banyak unit- unit pelayanan tetapi entah kenapa mereka banyak juga yang komplainnya melalui BAAK. BAAK STIKIM menerima keluhan mahasiswa dengan positive thinking dan dianggap sebagai kritikan dan saran supaya bisa lebih baik lagi. Peneliti menyimpulkan, sudah jelas sekali BAAK STIKIM menunjukkan banyaknya permasalahan dan hambatan-hambatan yang harus dihadapi dalam menerapkan strategi tersebut.

Terkait dengan kinerja di BAAK STIKIM, ada yang mengatakan jika dari angka 1 sampai 10 kinerja BAAK STIKIM hanya mendaptkan nilai 7,9 karena dilihat dari per individunya anggota BAAK STIKIM memang masih harus banyak belajar melakukan yang terbaik dalam pelayanan, menyampaikan informasi, dan menerima keluhan dengan baik. Peneliti juga melihat BAAK STIKIM memiliki kotak saran, jadi mahasiswa yang merasa kurang puas dengan pelayanan BAAK STIKIM atau dengan kinerja BAAKnya bisa langsung menyampaikan aspirasi mereka melalui kotak saran dan itu nanti akan di follow up oleh anggota BAAK STIKIM agar bisa ke depannya memberikan pelayanan dan memberikan informasi yang lebih baik kepada mahasiswa. Peneliti juga menemukan ada report beberapa bulan dari setiap tahun baik dari pencapaian kerja SDM masing-masing termasuk SDM BAAK STIKIM, tapi untuk kinerja biasanya tim manajemen representatif bagian mutu internal yang menjadi penilai khusus untuk bagian kinerja dengan menggunakan Key Performance Indicator. Peneliti juga menemukan pendapat lain tentang kinerja BAAK STIKIM yang mana mengatakan pelayanan BAAK STIKIM tentang administrasinya kelihatannya bagus karena bisa menanggulangi beberapa persoalan terkait aktivitas perkuliahan.

Dari semua pendapat yang ditemukan Peneliti dilapangan menunjukkan bahwa ada yang menilai kinerja BAAK STIKIM sudah baik dan ada juga yang masih menilai masih kurang baik. Bagaimanapun itu tetap saja kinerja BAAK STIKIM harus ditingkatkan agar tujuan dari BAAK STIKIM bisa tercapai.

\section{Kesimpulan}

Strategi public relations masih kurang maksimal dikarenakan tugas-tugas public relations dalam pelayanan informasi di STIKIM masih dilakukan secara fungsional manajemen dan BAAK STIKIM juga telah berupaya melakukan model public relations yang Two Way Symmetrical. Masih banyak permasalahan dan hambatan- hambatan yang harus dihadapi terkait kinerja BAAK STIKIM, terutama dalam berkomunikasi. Pandangan tentang kinerja BAAK STIKIM dari nara sumber terutama informan masih belum optimal dalam memberikan layanan informasi.

\section{References}

1. AW S. Komunikasi Perkantoran. Yogyakarta: Media Wacana.;

2. Mulyana D. Ilmu Komunikasi Suatu Pengantar. Bandung: PT Remaja Rosdakarya.;

3. Kasali R. Manajemen Public Relations. Jakarta: Pustaka Utama Grafiti.;

4. Moore F. Humas (membangun citra dengan komunikasi). Bandung: PT Remaja Rosda Karya;

5. Effendy, Onong U. Ilmu Komunikasi Teori dan Praktek. Bandung: PT. Remaja Rosdakarya; 2003.

6. Anggoro L. Teori Dan Profesi Kehumasan. Jakarta: PT Bumi Aksara.; 2008.

7. Abdurahman O. Dasar-dasar Public Relations. Jilid 12. Bandung: Citra Aditya Bakti; 2001. 


\section{JIKOM \\ Jurnal Ilmiah Komunikasi}

Volume 12, No.03, November. 2020

8. Sugiyono. Memahami Penelitian Kualitatif. Bandung: PT. Alfabeta; 2005.

9. Sugiyono. Memahami Penelitian Kualitatif dan R\&D. Bandung: PT. Alfabeta.; 2006.

10. Ruslan R. Metode Penelitian Public Relations dan Komunikasi. Jakarta: PT. Raja Grafindo Persada;

11. Sulistyo. No Title空間像再生型立体映像の 研究動向. Nhk技研. 2015;151:10-7.

12. Theaker A. The Public Relations Handbook. The Public Relations Handbook. 2016.

13. 1) H. Strategi Komunikasi Humas Dalam Membentuk Citra Pemerintahan Di Kota Baubau. MEDIALOG J Ilmu Komun. 2019;1(2):1-9.

14. Liliweri A. Sosiologi \& Komunikasi Organisasi. Jakarta: : Bumi Aksara.;

15. IriantaIriantara, Yosalra Y. Manajemen Strategi Public Relations. Jakarta: Ghalia Indonesia; 2004. 